\title{
Carbonate transport and within-reef patterns of bioerosion and sediment release by parrotfishes (family Scaridae) on the Great Barrier Reef
}

\author{
David R. Bellwood
}

Department of Marine Biology, James Cook University, Townsville, Queensland 4811, Australia

\begin{abstract}
The patterns of erosion and defaecation by 2 species of parrotfish Chlorurus gibbus and C. sordidus (family Scaridae) were examined at 2 sites on Lizard Island, Great Barrier Reef, Australia. Feeding behaviour and associated external bioerosion were examined at 3 spatial scales: reef zone, microhabitat and bite site. Feeding patterns in both species showed strong selectivity for specific reef zones, microhabitats and substratum types. Both species fed predominantly in the shallows, with strong preferences for coral stumps. C. gibbus strongly selected the reef crest and turf algae at both sites. C. sordidus showed differential selectivity at the 2 sites. It is suggested that these site and species differences are a result of interactions with territorial herbivores. In C. sordidus the patterns of feeding and defaecation across the reef were extremely similar. There was no net movement of material. In contrast, C. gibbus showed a strong preference for feeding in shallow reef zones, with defaecation marked by movement away from feeding areas to specific defaecation sites, usually in deeper areas of the reef. This resulted in an active net movement of carbonate off the reef.
\end{abstract}

KEY WORDS: Coral reef - Erosion · Feeding · Sediment production · Calcium carbonate · Fishes

\section{INTRODUCTION}

Parrotfishes have been identified as key components in bioerosion on coral reefs (Hutchings 1986, Kiene 1989). Most studies have provided an overall estimate of erosion. Spatial patterns of removal, however, are less well understood. There have been several suggestions that in the Indo-Pacific, there is considerable variability in scarid erosion rates at a range of spatial scales (Kiene 1989, Kiene \& Hutchings 1994). Recent studies have identified the principal bioeroding scarid species on the Great Barrier Reef, Australia (Bellwood \& Choat 1990, Bellwood in press). These studies also suggest that there will be high spatial variability in scarid erosion rates, ranging from differences in microhabitat and reef zone utilization patterns as a result of behavioural traits to major cross-shelf and ocean-level differences as a result of changes in scarid abundances. Indirect estimates of within-reef patterns of erosion of reef substrata support these suggestions (Kiene \& Hutchings 1994).
Although the feeding patterns of scarids have received considerable attention (e.g. Choat \& Robertson 1975, Bruce 1978, Hatcher 1981), this has provided only broad information on the feeding habits of the major bioeroding species. Detailed observations which may permit the spatial pattern of scarid erosion and sediment production (defaecation) to be determined were lacking.

The present study addresses the question of small-scale variability in erosion and sediment production by parrotfishes and its implications for net carbonate flow. It focuses on within-reef patterns, covering reef zones, substratum type and microhabitat utilization, and is based on direct observations of feeding and defaecation. The main objectives of the present study were: (1) to determine the extent of spatial variability and feeding preference at 3 scales: reef zone, microhabitat and bite site, (2) to determine defaecation patterns and net carbonate flow, and (3) to establish the extent of site specificity in these parameters. 


\section{MATERIALS AND METHODS}

All observations were undertaken on the fringing reefs around Lizard Island, a granitic island in the mid-shelf region of the northern Great Barrier Reef $\left(14^{\circ} 40^{\prime} \mathrm{S}, 145^{\circ} 28^{\prime} \mathrm{E}\right)$. Two sites were chosen for the behavioural observations (Fig. 1) following Choat \& Bellwood (1985) and Bellwood (in press).

Observations were restricted to 2 species, Chlorurus gibbus and C. sordidus, based on the results of Bellwood \& Choat (1990). All observations were made using SCUBA, with data recorded on underwater paper. To minimise the effects of interference by territorial herbivores on feeding behaviour (cf. Choat \& Bellwood 1985) all C. gibbus observations were based on individuals above $300 \mathrm{~mm} \mathrm{SL}$ (standard length) and, to reduce the influence of reproductive activity, all C. sordidus observations were based on initial phase individuals 150 to $200 \mathrm{~mm}$ SL (these also represent the most abundant size classes in the study areas).

Behavioural observations - zone utilization patterns. All observations were made in the summer between 7 December 1991 and 27 January 1992 during dawnto-dusk feeding observations (details in Bellwood in press). Feeding behaviour was recorded during replicate 5 min feeding observation periods. Upon arrival at the study site, the observer looked for specimens on the reef base, then swam in a rough zigzag pattern from the reef slope/crest to the inner reef flat, until a target individual was located. At this point the fish was given a few minutes to acclimatize to the diver before timed observations commenced. Observations were discontinued if the individual was lost during the $5 \mathrm{~min}$ period or if the individual showed any signs of disturbance (flight or hiding). Individuals frequently moved between zones during the 5 min observation period.

The study area is protected from all spearfishing activity and is regularly visited by researchers and sports divers. There is no fish feeding and both study

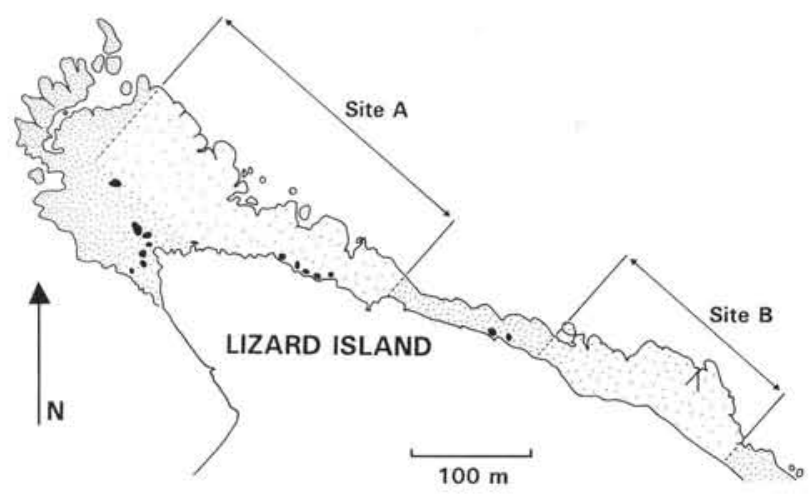

Fig. 1. Location of the study sites, off North Point, Lizard Island, Australia species appeared to be diver-neutral. Most observations were undertaken at a distance of 3 to $5 \mathrm{~m}$. Visibility usually ranged from 7 to $12 \mathrm{~m}$. Observations were discontinued if the visibility fell below $5 \mathrm{~m}$.

During the replicate 5 min observations, the following information was recorded: starting time, bites per minute, principal feeding location(s), number and location of defaecation events, distance moved between feeding location and defaecation location. Additional behavioural notes were taken, including the social behaviour of the focal individuals, the size of feeding groups, movement patterns, nature of interactions and swimming behaviour.

Reef zones were defined as follows (depths below chart datum). Reef base: a gently sloping region 6 to $10 \mathrm{~m}$ deep, extending up to $10 \mathrm{~m}$ from the bottom of the reef slope; reef slope: the steeply inclined face of the reef from $0-1$ to $6-9 \mathrm{~m}$; reef crest: the shallow ( 0 to $1 \mathrm{~m}$ deep) outer $5 \mathrm{~m}$ of the reef bordered on the seaward face by the sharply inclined reef slope; outer flat: the shallow region bordering the reef crest, extending in a belt 5 to $15 \mathrm{~m}$ from the junction of the reef slope/crest; inner flat: the shallow region between the outer reef flat and the shore; gullies: any discrete region in the reef crest or flats which is more than $0.2 \mathrm{~m}$ deeper than the surrounding reef. These are physical definitions used for ease of application. However, they are strongly associated with changes in topography and coral cover. Descriptions of the coral cover are provided in Nelson (1994).

A total of 131 and 155 observation periods of $5 \mathrm{~min}$ each were recorded at Sites A and B, respectively, for Chlorurus gibbus; for C. sordidus, the totals were 174 and 176 respectively. To examine zone utilization patterns, data are expressed as the mean proportion of bites taken from each zone in the observation period ( $\mathrm{n}=$ the number of observation periods; bites were allocated to the principal zones used during the observation period). To determine zonal preferences the total number of bites recorded in each zone during the whole study was compared with the relative area of that zone in the study area. Available areas of the various zones were based on area estimates taken from aerial photographs. The sizes of the study areas were chosen to encompass the entire feeding ranges of the study individuals at each site.

Microhabitat utilization patterns. Microhabitat utilization patterns were based on 5 microhabitat categories: live coral, dead coral (recognisable colonies), stumps (remnants of dead corals), coral rubble (detached fragments of coral) and the substratum (the reef matrix per se). Analyses are based on 25 observation periods of $5 \mathrm{~min}$ each at each site for Chlorurus gibbus and 21 and 20 periods for C. sordidus at Sites A and B respectively. 
The data are expressed as the mean $( \pm \mathrm{SE})$ proportion of bites recorded from each substratum type per observation period. The patterns of microhabitat utilization at the 2 sites were compared using a chisquared homogeneity test on the total number of bites recorded from each microhabitat type at each site. Feeding preferences were determined by comparing utilization rates with microhabitat availability (see section 'Substratum availability' below).

Bite locations. Direct observations were made by following target individuals (of noted size and species) until the exact location of a bite could be clearly seen. Focusing on this location the observer swam to the position of the bite and located the bite scar (marked by dislodged algae and/or a gouged surface). Bites may leave 1 or 2 scars corresponding to the marks left by the premaxillae and dentaries (Bellwood \& Choat 1990). The location of the scar or scars was then recorded with regard to the substratum type (algae or calcareous algae). A minimum of 44 bites for each species were examined at each of the 2 sites. Substratum type utilization patterns were compared using chi-squared tests.

Substratum availability. To determine if either or both species showed a preference for a given microhabitat or substratum type, replicate transects were undertaken to determine substratum availability. At each study site, within each reef zone, 3 transects were examined. Each transect was $30 \mathrm{~m}$ long and ran parallel to the reef edge. At each $1 \mathrm{~m}$ point along the transect the form of the substratum was recorded at the tape and $1 \mathrm{~m}$ either side. This gave a total of 102 point records per transect. At each point the microhabitat form (5 types listed above plus sediment and soft coral categories) and substratum type (turf or calcareous algae) were recorded.

To allow for the different areas of each zone, availability was corrected by multiplying the relative proportion of a given microhabitat/cover in each zone by the relative area of that zone as a proportion of the whole study area. This corrected availability value was then used in the electivity indices. The area of each zone was calculated by measuring the area covered by each zone on an aerial photograph of the study sites.

This survey covered 4 zones at Site A (inner flat, outer flat, gullies and crest) and 3 at Site B (no gullies present). These included all feeding zones. Given the mobility of the species, the substrata are all considered 'available' in that all were within the feeding ranges of both study species and all could be, and often were, traversed within a 5 min observation period.

Statistical procedures. Prior to analysis by ANOVA, homogeneity and normality of variances was tested using Bartlett's test, Cochran's test or Wilk-Shapiro statistics. Heteroscedastic data were $\log _{10^{-}}$or arcsin- transformed prior to retesting and analysis. Consistently heteroscedastic data were analysed using nonparametric procedures following Zar (1974). Feeding preference was determined using Vanderploeg \& Scavia's electivity index $\left(E^{*}\right)$ following Lechowicz (1982).

\section{RESULTS}

\section{Reef zone utilization patterns}

\section{Feeding patterns}

In terms of feeding, the most striking features were that both species fed predominantly in shallow water but with Chlorurus sordidus showing markedly different patterns at the 2 sites (Figs. $2 \& 3$ ). Feeding by $C$. sordidus at Site A was concentrated in the shallow $(<4 \mathrm{~m})$ rubble-filled gullies that occur in the outer/ inner reef flat. At Site B these gullies were absent, and feeding was concentrated in the shallow crest and outer flat. The only gullies available at Site B are deep $(>6 \mathrm{~m})$ narrow clefts in the reef. Despite these site differences in C. sordidus, the feeding patterns of $C$. gibbus were very consistent, with 87 to $97 \%$ of bites being restricted to areas no more than $1 \mathrm{~m}$ below chart datum (CD).

Reef zone utilization patterns (comparing total bites in each zone and total area available) are summarized in Fig. 4 with electivity indices given in Fig. 5. The
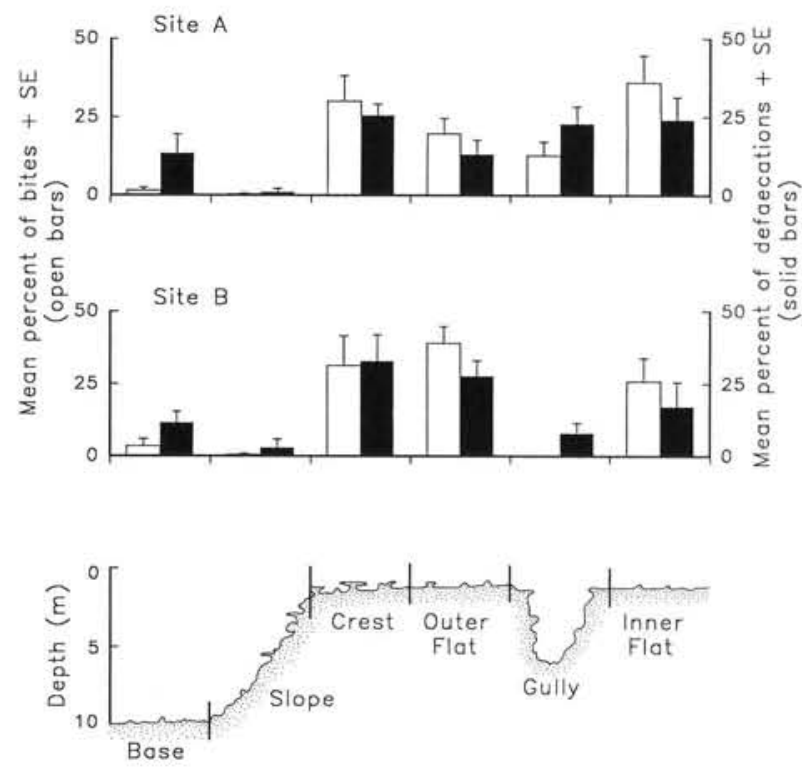

Fig. 2. Chlorurus gibbus. Spatial patterns of feeding and defaecation. Rates are expressed as the mean percent of the total bites/defaecations recorded per day from each location ( $+\mathrm{SE}, \mathrm{n}=5$ days for each site) 

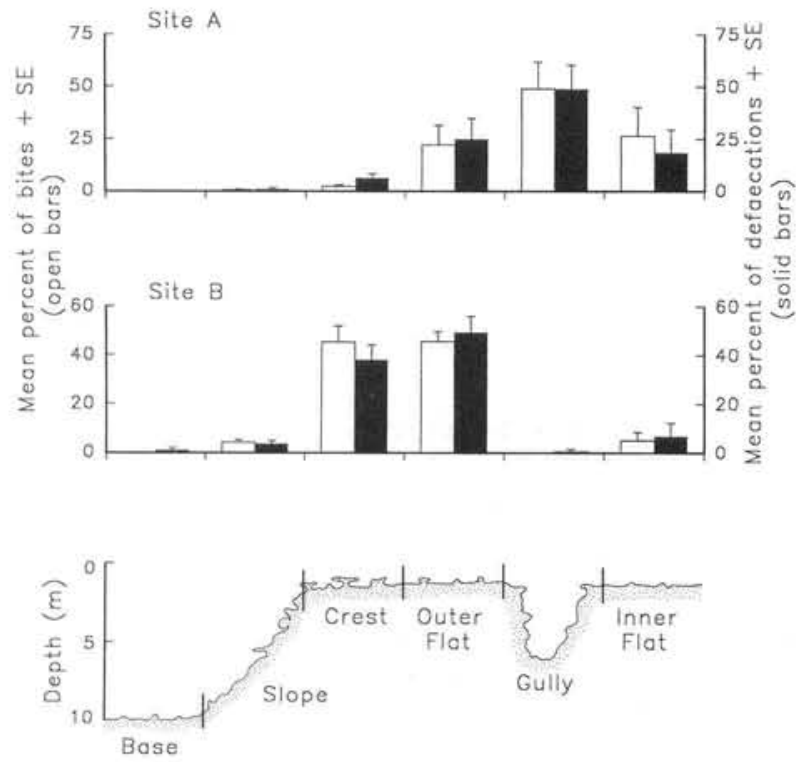

Fig, 3. Chlorurus sordidus. Spatial patterns of feeding and defaecation. Rates are expressed as the mean percent of the total bites/defaecations recorded per day from each location ( $+\mathrm{SE}, \mathrm{n}=5$ days at each site)

results show a clear preference by $C$. gibbus for the reef crest and to a lesser extent the outer flat. C. sordidus shows a preference for gullies at Site $\mathrm{A}$, the crest at Site B and to a lesser extent the outer flat at both sites (Fig. 5).

\section{Defaecation patterns}

Defaecation patterns were quite striking. In Chlorurus sordidus, relative rates of feeding and defaecation in the various zones were very similar (Fig. 3). This suggests that defaecation events occurred roughly in

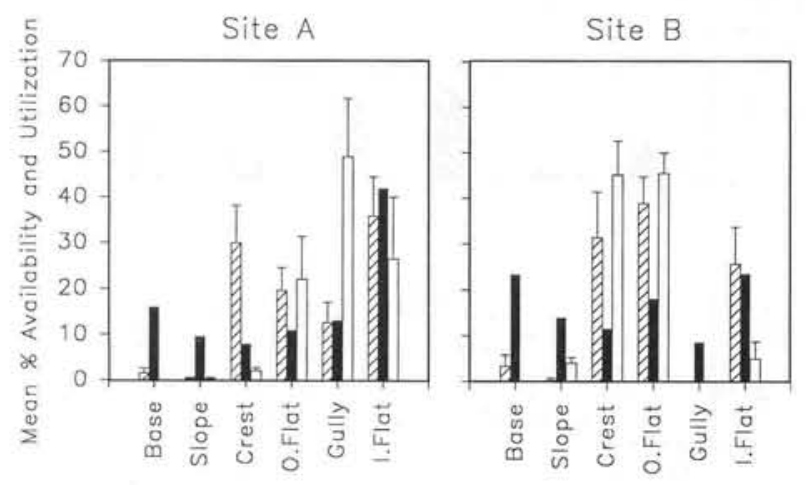

Fig. 4. Chlorurus gibbus and C. sordidus. Reef zone availability and utilization patterns. C. gibbus (hatched bars) and $C$. sordidus (open bars) as mean percent utilization $+\mathrm{SE}$; availability (solid bars) represents corrected values for each site

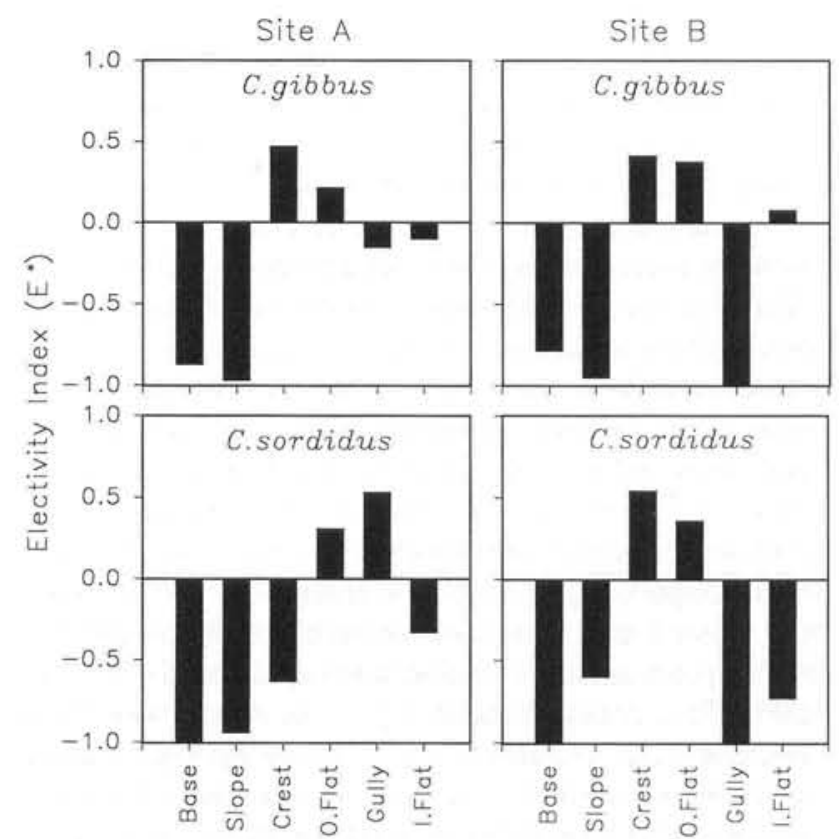

Fig. 5. Chlorurus gibbus and C. sordidus. Reef zone utilization patterns by electivity index

proportion to the number of bites taken in that zone. In contrast, in C. gibbus there appeared to be an active net movement of material (Fig. 2). In shallow areas, the proportion of defaecation events was relatively low, whilst deeper areas had a relatively high proportion of defaecation events, particularly in gullies and over the reef base.

\section{Behaviour}

The above results were supported by direct observations of feeding and defaecation behaviour. Defaecation patterns were quantified by recording the number of times an individual moved between zones to defaecate (vs defaecation within the zone), its initial (feeding) location and the eventual defaecation location (Table 1). In Chlorurus gibbus, approximately one-third of all defaecation events involved a movement between reef zones, compared to only 3 to $6 \%$ in C. sordidus.

Chlorurus gibbus usually fed in small groups of 3 to 8 individuals in the shallow portions of the reef. Feeding was often concentrated in 'favoured' areas. These were frequently within areas defended by the territorial acanthurid Acanthurus lineatus. Periodically 1 or a number of individuals would swim away from the feeding area to defaecate. The distance travelled would often be 10 to $30 \mathrm{~m}$ and, if a long way from the feeding area, this distance was often 
Table 1. Chlorurus gibbus and C. sordidus. Defaecation movements are expressed as the mean percentage of defaecation events ( \pm SE) which involved a movement between reef zones. For each location $n=5$ (based on the total number of defaecations observed in $1 \mathrm{~d}$ with $>5 \mathrm{~h}$ of observation each day). Analysis is based on a nonparametric ANOVA following Zar (1974). Total mean square $=42$

\begin{tabular}{|lcrc|}
\hline Species & Site A & \multicolumn{2}{c|}{ Site B } \\
\hline C. gibbus & $39.8 \pm 12.0$ & & $31.2 \pm 4.3$ \\
C. sordidus & $3.4 \pm 1.4$ & & $6.1 \pm 2.0$ \\
ANOVA & & & \\
Source of variation & Sum of squares & df & p \\
\hline Species & 941 & 1 & $<0.001$ \\
Location & 450 & 1 & $<0.001$ \\
Spp. $\times$ Loc. & 4919 & 1 & $<0.001$ \\
\hline
\end{tabular}

covered quite rapidly. Individuals feeding on the outer flat or crest usually swam to a gully or off the reef crest to defaecate. Defaecation near the reef crest was often associated with cleaning by Labroides dimidiatus.

In Chlorurus gibbus, a movément to defaecate was most clearly apparent when examined directly. Few C. gibbus individuals defaecated in the immediate feeding area, most would move a few meters away from the feeding location before defaecating. Within the reef crest zone, defaecation sites were often on promontories or in indentations, whilst fish on the inner flat swam out of the feeding area to defaecate. In some areas, a favoured 'defaecation site' could be identified. In this case, individuals would swim 5 to $20 \mathrm{~m}$ from the feeding area to defaecate at the site. At Site A, a school of $C$. gibbus were feeding near a defaecation site. They defaecated almost exclusively within a single pit $(2 \times$ $3 \mathrm{~m}, 30 \mathrm{~cm}$ deep), with 19 defaecation events recorded in approximately $30 \mathrm{~min}$. These sites were used over several days and were used repeatedly over a period of several months.

The data summarized in Fig. 2 and Table 1 point to a movement by Chlorurus gibbus between the feeding and defaecation sites. The direction of this movement is shown in Fig. 6 with the net movement by both species summarized in Table 2 . These defaecation patterns show an active and direct net movement of material by $C$. gibbus from shallow feeding areas to deeper regions. The pattern is the same at both sites.
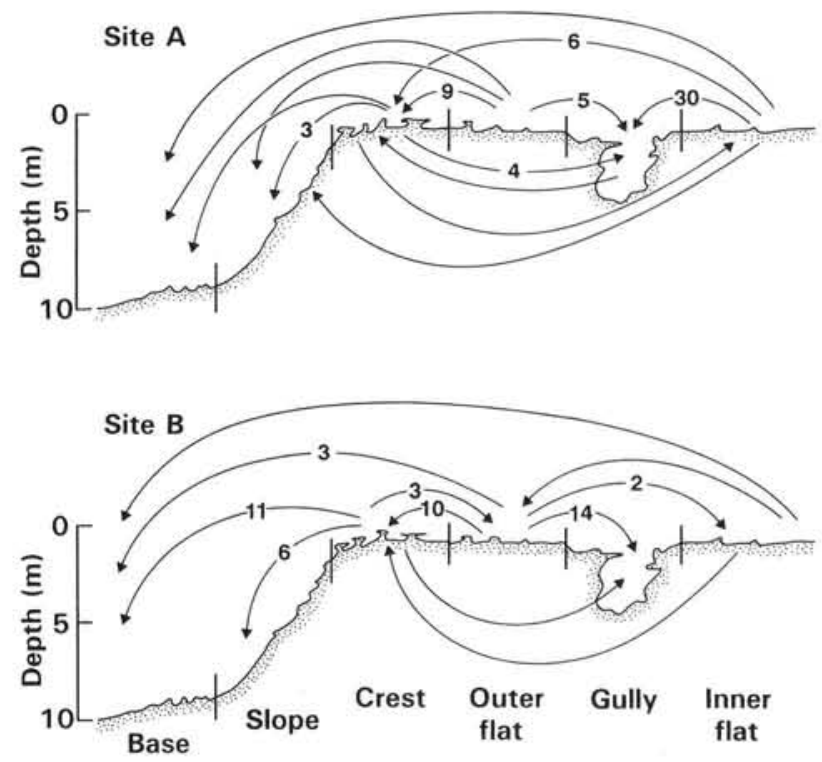

Fig. 6. Chlorurus gibbus. Movement between reef zones prior to defaecation. Arrows start at the reef zone where feeding ceased and terminate in the zone where defaecation occurred. Numbers indicate the frequency of movements between zones. Net movement is summarized in Table 2

In contrast to Chlorurus gibbus, C. sordidus shows little movement associated with defaecation. Most defaecation events occur in the immediate vicinity of feeding sites or when swimming between feeding locations. C. sordidus occasionally defaecates whilst feeding. In only 3.4 to $6.1 \%$ of instances was defaecation associated with a move of location (Table 1). No distinct movements associated with defaecation were recorded and there is no clear directional movement (Table 2).

Table 2. Chlorurus gibbus and C. sordidus. Net movement prior to defaecation, expressed as the net movement in or out of each reef zone prior to defaecation. Numbers in parentheses refer to the number of movements into the zone to defaecate over the number of movements out of that zone to defaecate elsewhere (in/out). Bold type is used where movement in exceeds movement out, or vice versa, by 10 or more times

\begin{tabular}{|lccccccc|}
\hline Species & Location & Base & Slope & Crest & $\begin{array}{c}\text { Outer } \\
\text { flat }\end{array}$ & Gully & $\begin{array}{c}\text { Inner } \\
\text { flat }\end{array}$ \\
\hline C. gibbus & Site A & IN & IN & IN & OUT & IN & OUT \\
& & $(3 / 0)$ & $(5 / 0)$ & $(16 / 9)$ & $(0 / 16)$ & $(39 / 1)$ & $(1 / 38)$ \\
& Site B & IN & IN & OUT & OUT & IN & - \\
& & $(15 / 0)$ & $(6 / 0)$ & $(11 / 21)$ & $(14 / 26)$ & $(15 / 0)$ & $(2 / 3)$ \\
C. sordidus & Site A & & & - & IN & OUT & - \\
& & $(0 / 0)$ & $(0 / 0)$ & $(0 / 1)$ & $(8 / 2)$ & $(2 / 7)$ & $(1 / 0)$ \\
& Site B & IN & IN & OUT & IN & IN & OUT \\
& & $(3 / 0)$ & $(6 / 0)$ & $(1 / 11)$ & $(6 / 2)$ & $(3 / 0)$ & $(0 / 4)$ \\
\hline
\end{tabular}




\section{Microhabitat utilization}

The 2 species shared a similar pattern of microhabitat utilization (Fig. 7). In both species at both locations, more than half of all bites were from a single microhabitat, i.e. coral stumps. Both species showed a strong preference for stumps at both sites (Fig. 8). Chlorurus gibbus also showed a consistent preference for dead corals. Substrata for which there was a consistently negative selectivity included sediment and soft corals, both of which were rare. However, live coral which was relatively abundant was also consistently underutilized by both species. Rubble and the substratum were used by $C$. sordidus but both were consistently underutilized by $C$. gibbus.

\section{Substratum type utilization}

In addition to microhabitat utilization patterns, the nature of the substratum surface in the exact location of the bite was examined. The results are quite striking. Chlorurus gibbus was very consistent with no site effect in substratum use or preference (Table 3, Fig. 9). At both sites, C. gibbus fed predominantly on substrata covered in turf algae, with a strong positive preference for this substratum type (vs coralline algae; Fig. 9). There was no significant difference in its pattern of substratum use at the 2 sites (Table $3 ; \chi^{2}=0.0139$, $\mathrm{p}=0.906,1 \mathrm{df})$.

At Site A the feeding mode of Chlorurus sordidus was very similar to that of $C$. gibbus, i.e. feeding predominantly on turf algae. Indeed, the 2 species did not differ in their utilization patterns $\left(\chi^{2}=1.196, p=0.27\right.$, $1 \mathrm{df})$ and their preferences appear to be comparable (Fig. 9). At Site B, however, C. sordidus differed in
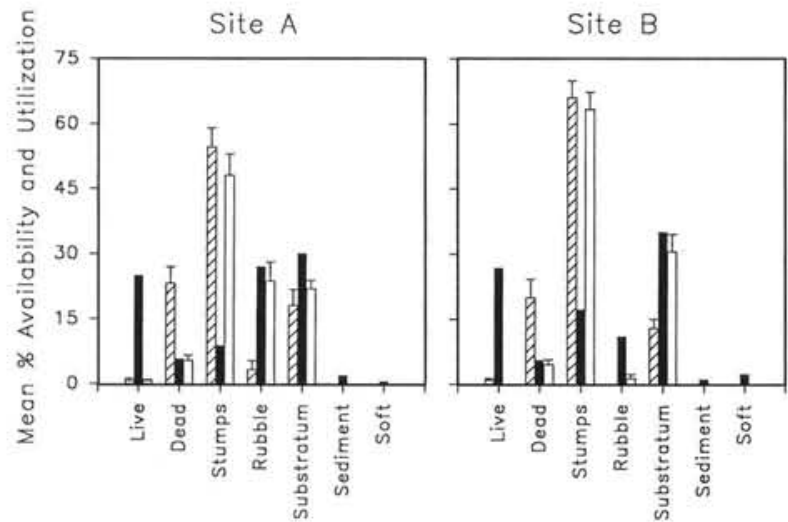

Fig. 7. Chlorurus gibbus and C. sordidus. Microhabitat availability and utilization patterns. C. gibbus (hatched bars), C. sordidus (open bars) as mean percent $+\mathrm{SE}$; availability (solid bars) represents corrected values for each site

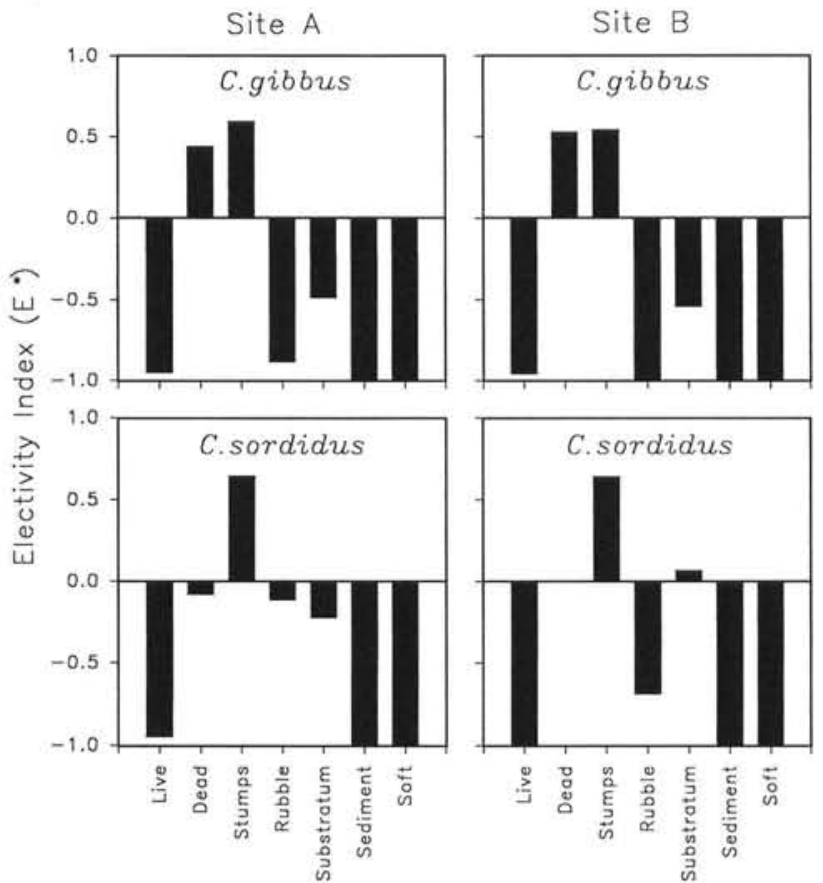

Fig. 8. Chlorurus gibbus and C. sordidus. Microhabitat utilization patterns by electivity index

its feeding pattern from both $C$. sordidus at Site A $\left(\chi^{2}=34.75, \mathrm{p}<0.001,1 \mathrm{df}\right)$ and from $C$. gibbus at Site B (Table $3 ; \chi^{2}=48.51, p<0.001,1$ df). At Site B, C. sordidus showed a positive preference for calcareous substrata rather than turf algae.

To some extent these data reflect the relative abundance of calcareous algae at the 2 sites, with more calcareous algae at Site B. It appears that this difference between the 2 species may reflect their relative abilities to access the turf algae. At Site B in particular, Chlorurus gibbus was frequently seen targeting Acanthurus lineatus territories. These areas are often unavailable to $C$. sordidus as this species is usually excluded from territories by the territorial
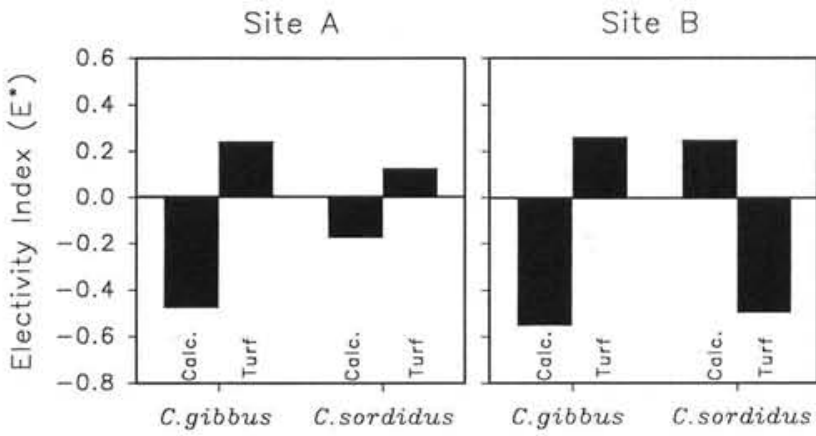

Fig. 9. Chlorurus gibbus and C. sordidus, Substratum type utilization patterns by electivity index. Calc.: calcareous algae; Turf: epilithic turf algae 
Table 3. Chlorurus gibbus and C. sordidus. Comparison of substratum type availability and utilization patterns, expressed as the number of bites taken from each substratum type. Substratum type is based on the precise location of the bite. Availability estimates are corrected values as described in the text

\begin{tabular}{|lcccccc|}
\hline & \multicolumn{1}{c}{\begin{tabular}{c} 
Site A \\
\cline { 2 - 5 }
\end{tabular}} & C. gibbus & C. sordidus & $\begin{array}{c}\text { Available } \\
\text { (est. \%) }\end{array}$ & C. gibbus & $\begin{array}{c}\text { C. sordidus } \\
\text { Available } \\
\text { (est. \%) }\end{array}$ \\
\hline Calcareous algae & 4 & 9 & 31.5 & 6 & 50 & 44.1 \\
Turf algae & 39 & 44 & 68.5 & 54 & 55.9 \\
\hline
\end{tabular}

activities of A. lineatus (cf. Choat \& Bellwood 1985). C. sordidus must therefore forage in the open areas which, at this location, were dominated by calcareous algae.

\section{DISCUSSION}

Although estimated rates of bioerosion are highly variable, few studies have examined the spatial pattern of this variability. Most studies of bioerosion examine only 1 or 2 taxa, with the vast majority of studies concentrating on providing an overall estimate of erosion rates at a single site. This applies to internal and external eroders, and particularly to erosion by scarids (parrotfishes). The only studies which have examined the extent of spatial or temporal variability in scarid bioerosion are Kiene (1989) and Kiene \& Hutchings (1994). Both studies suggest that there is considerable spatial variability in external erosion rates. The results of the present study describe the extent of this variability in erosion rates at a range of spatial scales and provide an explanation for the patterns seen.

In previous studies it has been shown that scarid bioerosion is largely restricted to a small group of functional 'excavators' (Bellwood \& Choat 1990), most of which are now placed in the genus Chlorurus (Bellwood 1994). Of these species, erosional activities in a given area may be restricted to only 1 or 2 species (Bellwood in press), which may have unusual feeding and habitat utilization patterns (Choat \& Bellwood 1985, Bellwood \& Choat 1990).

The results of the present study revealed major differences between the 2 species in terms of feeding patterns and preferences at all of the 3 spatial scales examined: reef zones, microhabitat and substratum type. The results suggest that a great deal of the recorded spatial variability may be explained by behavioural attributes of the dominant external eroding species. In addition, it appears that there is considerable site-specific modification of feeding habits, probably as a result of behavioural interactions with territorial herbivores.

\section{Feeding patterns and preferences}

Both Chlorurus gibbus and C. sordidus show a strong positive selectivity for specific zones, microhabitats and substratum types. Both species feed predominantly and selectively in shallow areas. C. gibbus consistently selects turf algae, coral stumps and the reef crest. The feeding patterns of $C$. sordidus are similar in terms of preferring stumps in shallow areas but there are marked site effects in the utilization and selectivity of zones and substratum types.

Despite the number of records of scarids feeding on live corals, both species took less than $2 \%$ of all bites from live corals and both showed a strong avoidance of live corals as a feeding site (Fig. 8).

The differences observed between the 2 species may be the result of behavioural interactions with territorial herbivores, especially the 'farming' acanthurid Acanthurus lineatus. Previous studies on this species at the same study sites have revealed variable responses of this species towards scarids (Choat \& Bellwood 1985). In most instances Chlorurus gibbus is permitted to feed within the territories of $A$. lineatus whilst smaller scarids, including $C$. sordidus, are usually attacked and vigorously evicted. Choat \& Bellwood (1985) recorded C. gibbus feeding frequently within A. lineatus territories.

Thus, when one examines feeding patterns, Chlorurus gibbus probably does display a true indication of preferences or selectivity as all zones, microhabitats and substrata are available for grazing. In contrast, for $C$. sordidus the same areas may not be equally available. For example, the territories of Acanthurus lineatus may be out of bounds to $C$. sordidus because of the aggressive behaviour of $A$. lineatus towards other herbivorous fishes (Choat \& Bellwood 1985).

Previous work has suggested that Acanthurus lineatus territories are desirable feeding areas for scarids and would constitute a preferred food source (Robertson et al. 1979, Choat \& Bellwood 1985). From data in Choat \& Bellwood (1985) it appears that these territories comprise a large proportion of Chlorurus gibbus bites and may be a target area. This is consistent with the observations in the present study and 
may, in part, explain the preference by C. gibbus for the crest, where $A$. lineatus territories are concentrated.

For Chlorurus sordidus, the range of available feeding areas may differ because of the presence of Acanthurus lineatus. A large proportion of the crest (at Site A especially) and parts of the flats are colonized by A. lineatus and may be unavailable to $C$. sordidus, which must therefore feed in the remaining habitats. This may explain the observed site effects. At Site A there is abundant turf algae outside $A$. lineatus territories and extensive shallow gullies with algae-covered coral rubble. In contrast, at Site B, there are few shallow gullies and the flats have an extensive cover of coralline algae. These differences may drive the 'preferences' by $C$. sordidus for algae and gullies at Site A vs coralline algae and the crest/outer flat at Site B.

The question remains why Acanthurus lineatus permits Chlorurus gibbus to feed in its territory but not C. sordidus. Both are excavators and both seem to select the same microhabitats and substratum types. This was addressed by Choat \& Bellwood (1985) without resolution. Another factor which may account for the differential attack rates by $A$. lineatus towards C. gibbus and $C$. sordidus may be the defaecation patterns of the 2 species. Unlike C. sordidus, C. gibbus rarely defaecates at its feeding site. Purcell \& Bellwood (1993) suggest that sediment may be detrimental to the feeding efficiency of $A$. lineatus. The difference between the 2 scarid species, therefore, may not be related to their feeding habits but to their defaecation habits.

Acanthurus lineatus tolerates the detritivorous acanthurid Ctenochaetus striatus feeding within its territory. Previous authors have suggested that this may be due to different diets (Choat \& Bellwood 1985) or sediment removal by Ctenochaetus (Purcell \& Bellwood 1993). However, defaecation patterns may also play a role. C. striatus usually defaecates in specific sites, often depressions, at the edge of their territories or feeding areas (Clements 1991, Bellwood pers. obs.). In comparison, the roving acanthurid A. nigrofuscus appears to defaecate over feeding areas (Clements 1991). A. lineatus tolerates $C$. striatus but vigorously excludes A. nigrofuscus.

Previous studies have suggested that the activities of territorial herbivores increases internal bioerosion (Risk \& Sammarco 1982, Kiene \& Hutchings 1994, but see Sammarco et al. 1987). For external bioerosion, the interactions between mobile and territorial herbivores appear to be complex. The presence of Acanthurus lineatus territories may increase erosion rates within the territory by Chlorurus gibbus, but decrease erosion rates by $C$. sordidus. Small-scale patterns of external erosion may, therefore, be a function of not only the abundance of the eroding species but also the abundance and species of territorial herbivores and their local behavioural traits (cf. Choat \& Bellwood 1985).

Overall, it appears that Chlorurus gibbus select algal turf on coral stumps on the reef crest. This includes areas within Acanthurus lineatus territories. In contrast, C. sordidus appears to select those substrata which are relatively abundant and free of $A$. lineatus territories. In this case 'selection' may merely reflect effective availability.

\section{Carbonate removal and deposition - ecological and geological implications}

\section{Small-scale utilization patterns}

The results support the earlier findings of Bellwood \& Choat (1990) who demonstrated that feeding by the excavating forms was concentrated on convexities. However, the data point to an even more specific pattern, with removal of material predominantly from a single microhabitat type (dead coral stumps). For both species, this is the dominant feeding surface and is strongly selected. There are similar preferences displayed in terms of reef zones, with strong selection for shallow regions, especially the reef crest. The consequences of this restricted feeding activity are 2-fold. Firstly, it may significantly modify topography and secondly, it has serious implications when using experimental blocks to determine external erosion rates.

The specific nature of feeding by excavating scarids strongly suggests that their activities will modify the reef topography. Given the estimates of Bellwood (in press), up to $5.6 \mathrm{~kg} \mathrm{~m}^{-2} \mathrm{yr}^{-1}$ may be removed by excavating scarids. This is an average value. The vast majority of this would be removed from raised substrata, particularly dead coral stumps in the shallow reef crest and reef flat regions. By selectively eroding raised features, this action would continually decrease topographic rugosity. Erosion of raised substrata by large scarids may account for the decreased topographic complexity in heavily grazed areas reported by Miller (1982) and the rapid external erosion of dead plate corals reported by Musso (1994). It is to be expected that areas with large populations of excavating scarids would have high erosion rates.

The second consequence of the selective nature of scarid feeding is in the interpretation of erosion rates based on experimental substrata as used by Davies \& Hutchings (1983), Kiene (1985, 1989), Sammarco \& Carlton (1986), Hutchings et al. (1992) and Kiene \& Hutchings (1994). In these experimental studies pieces of coral substrata are placed on raised grids that are 
attached to the reef. As such, they are analogous to dead coral stumps and would therefore be likely to be subject to the highest possible levels of external erosion. In examining the results of these studies, therefore, it should be taken into consideration that the recorded erosion rates per $\mathrm{m}^{2}$ will be much higher than those from an equivalent area of adjacent reef. The latter is comprised of heterogeneous substrata with only a limited area of raised coral substrata. Erosion rates from experimental substrata are effectively erosion rates per $\mathrm{m}^{2}$ of dead coral stumps. As such the external erosion rates are probably outside the maximum rates from normal substrata in that region.

Conversely, these experimental substrata may greatly underestimate the relative importance of internal bioerosion as: (1) rates would appear low by comparison, (2) grazing may actively decrease internal erosion (Risk \& Sammarco 1982, Kiene \& Hutchings 1994), and (3) available matrix would be decreased thus limiting the volume available for internal erosion. In addition, as internal bioerosion appears to display spatial variability in natural substrata similar to that observed for external bioerosion (cf. Hutchings et al. 1992), it is important when comparing ínternal vs external bioerosion that the 2 types are compared at appropriate spatial scales.

\section{Large-scale utilization and defaecation patterns}

The dominant bioeroding species in the study area, Chlorurus gibbus (Bellwood in press), not only removes material from a restricted range of substrata, it also defaecates in an equally restricted manner. The result is an active net flow of freshly eroded carbonate material from dead corals in the shallows to depressions in or off the reef. This represents a large proportion of the estimated $1.018 \pm 186 \mathrm{~kg}( \pm 95 \%$ confidence interval) of carbonate removed by each individual in a year (Bellwood in press).

Deposition of sediments in this manner was very patchy. For Chlorurus gibbus, defaecation sites and erosion sites are spatially separate and favoured defaecation pits will receive a much higher sediment input than other areas. In one instance a group of 4 to 8 individual $C$. gibbus appeared to use just 2 defaecation sites over a period of $4 \mathrm{~d}$. In this time, approximately $67 \mathrm{~kg}$ of material was deposited in 2 areas, each no more than $6 \mathrm{~m}^{2}$. Examination of sediment deposition patterns on reefs must consider the behavioural activities of large mobile bioeroders. Similar active movement of reworked sediments has been observed in some non-eroding scarids and detritivorous acanthurids (Bellwood pers. obs.). In C. sordidus, however, material is deposited in the same vicinity as its re- moval. Deposition, therefore, is determined by the same factors that determine feeding patterns. There is no net movement.

Davies (1983) suggests that at One Tree Reef in the southern Great Barrier Reef, erosion and accumulation of sediment did not occur until the reef grew into shallow water, with the windward margin being identified as the primary source of sediment. Although this initiation of sediment production and retention may be largely the result of the reef growing into a high energy zone, it is also associated with the reef's growth into a high erosion zone. The results of the present study show a clear preference of bioeroding scarid species for shallow feeding sites. Given the relative importance of scarids as bioeroders on some IndoPacific reefs (Bellwood in press), their activities may be a critical factor in determining the rate and nature of sedimentation in mature reefs.

Acknowledgements. This work was undertaken at the Lizard Island Research Station, a facility of the Australian Museum. The skill and kindness of the staff of LIRS are gratefully acknowledged. I thank J. H. Choat for advice and comments on earlier versions of the manuscript. I also thank E. Hutchison, A. Newton and M. Marnane for their invaluable assistance, either in the field or with subsequent data analysis. Additional field support was provided by S. Purcell. Thanks to O. Bellwood for her assistance in manuscript preparation. This work was supported by the Australian Research Council and a Merit Research Grant from James Cook University.

\section{LITERATURE CITED}

Bellwood, D. R. (1994). A phylogenetic study of the parrotfishes family Scaridae (Pisces: Labroidei), with a revision of genera. Rec. Aust. Mus. Supp. 20: 1-86

Bellwood, D. R. (in press). A direct estimate of bioerosion by two parrotfish species Chlorurus gibbus and Chlorurus sordidus on the Great Barrier Reef, Australia. Mar. Biol.

Bellwood, D. R., Choat, J. H. (1990). A functional analysis of grazing in parrotfishes (family Scaridae): the ecological implications. Environ. Biol. Fish. 28: 189-214

Bruce, R. W. (1978). Intraspecific organization in parrot fish. In: McLusky, D. S., Berry, A. J. (eds.) Physiology and behaviour of marine organisms. Proc. 12th Eur. Symp. Mar. Biol., Stirling, Scotland. Pergamon Press, Oxford, p. $229-236$

Choat, J. H., Bellwood, D. R. (1985). Interactions amongst herbivorous fishes on a coral reef: influence of spatial variation. Mar. Biol. 89: 221-234

Choat, J. H., Robertson, D. R. (1975). Protogynous hermaphroditism in fishes of the family Scaridae. In: Rheinboth, $\mathrm{R}$. (ed.) Intersexuality in the animal kingdom. SpringerVerlag, Heidelberg, p. 263-283

Clements, K. D. (1991). Gut microorganisms of surgeonfishes (family Acanthuridae). Ph.D. thesis, James Cook University, Townsville

Davies, P. J. (1983). Reef growth. In: Barnes, D. J. (ed.) Perspectives on coral reefs. Published for the Australian Institute of Marine Science by Brian Clouston Publishing, Manuka, p. 69-106 
Davies, P. J., Hutchings, P. A. (1983). Initial colonization, erosion and accretion on coral substrate: experimental results, Lizard Island, Great Barrier Reef. Coral Reefs 2: 27-37

Hatcher, B. G. (1981). The interaction between grazing organisms and the epilithic algal community of a coral reef: a quantitative assessment. Proc. 4th Int. Coral Reef Symp., Manila 2: 515-524

Hutchings, P. A. (1986). Biological destruction of coral reefs a review. Coral Reefs 4: 239-252

Hutchings, P. A., Kiene, W. E., Cunningham, R. B., Donnelly, C. (1992). Spatial and temporal patterns of non-colonial boring organisms (polychaetes, sipunculans and bivalve molluscs) in Porites at Lizard Island, Great Barrier Reef. Coral Reefs 11: 23-31

Kiene, W. E. (1985). Biological destruction of experimental coral substrates at Lizard Island, Great Barrier Reef, Australia. Proc. 5th Int. Coral Reef Symp. 5: 339-344

Kiene, W. E. (1989). A model of bioerosion on the Great Barrier Reef. Proc. 6th Int. Coral Reef Symp. 3: 449-454

Kiene, W. E., Hutchings, P. A. (1994). Experimental investigations on patterns in the rates of bioerosion at Lizard Island, Great Barrier Reef. Coral Reefs 13: 91-98

Lechowicz, M. J. (1982). The sampling characteristics of electivity indices. Oecologia 52: 22-30

Miller, A. C. (1982). Effects of differential fish grazing on the community structure of an intertidal reef flat at Enewetak Atoll, Marshall Islands. Pacif. Sci. 36: 467-482

This article was presented by G. F. Humphrey (Senior Editorial Advisor), Sydney, Australia
Musso, B. M. (1994). Rates of skeletal degradation following death in three species of Acropora. Proc. 7 th Int. Coral Reef Symp., Guam 1: 413-418

Nelson, V. M. (1994). Patterns of cover, diversity and spatial arrangement of benthos at Lizard Island, Great Barrier Reef. Proc. 7th Int. Coral Reef Symp., Guam 2: 827-832

Purcell, S. W., Bellwood, D. R. (1993). A functional analysis of food procurement in two surgeonfish species, Acanthurus nigrofuscus and Ctenochaetus striatus (Acanthuridae). Environ. Biol. Fish. 37: 139-159

Risk, M. J., Sammarco, P. W. (1982). Bioerosion of corals and the influence of damselfish territoriality: a preliminary study. Oecologia 52: 376-380

Robertson, D. R., Polunin, N. V. C., Leighton, K. (1979). The behavioural ecology of three Indian Ocean surgeonfish (Acanthurus lineatus, A. leucosternon and Z. scopas): their feeding strategies, and social mating systems. Environ. Biol. Fish. 4: 125-170

Sammarco, P. W., Carlton, J. H. (1986). Effects of grazing and damselfish territoriality on bioerosion of dead corals: direct effects. J. exp. mar. Biol. Ecol. 98: 1-19

Sammarco, P. W., Risk, M. J., Rose, C. (1987). Effects of grazing and damselfish territoriality on internal bioerosion of dead corals: indirect effects. J. exp. mar. Biol. Ecol. 112: 185-199

Zar, J. H. (1974). Biostatistical analysis. Prentice Hall, Englewood Cliffs, NJ

Manuscript first received: June 27, 1994

Revised version accepted: September 15, 1994 